\title{
Potencializando o ensino da lógica com uso de dispositivos móveis mediado pelo método Peer Instruction
}

\author{
Maria Angélica Figueiredo Oliveira ${ }^{1}$, Marijane Rechia ${ }^{2}$ \\ ${ }^{1}$ Pós-Graduação em Informática na Educação - \\ Centro -Av. Paulo Gama, 110 -Anexo III - $3^{\circ}$ andar - \\ CEP: 90040060 - Universidade Federal do Rio Grande do Sul (UFRGS) \\ Porto Alegre - RS - Brazil. \\ ${ }^{2}$ Programa de Pós-Graduação em Educação - Av. Roraima no 1000 \\ Cidade Universitária - Bairro Camobi - CEP: 97105900 - \\ Universidade Federal de Santa Maria (UFSM) \\ Santa Maria - RS. \\ mariaangelicafo@gmail.com, mjrechia@gmail.com
}

\begin{abstract}
This research presents an experience report using the Peer Instruction method, combined with the use of mobile devices in the classes of Logic of a Technical Course in Computing integrated to High School. The results obtained in the experience realized in 2017 demonstrate a performance of learning, in relation to the content, significantly superior to the students in the same discipline in the year of 2016, emphasizing aspects like the sharing of ideas and the positive confrontation between the peers, in addition to a greater interaction between the class.
\end{abstract}

Resumo. Esta pesquisa apresenta um relato de experiência da utilização do método Peer Instruction, combinado ao uso de dispositivos móveis nas aulas de Lógica de um curso Técnico em Informática integrado ao Ensino Médio. Os resultados obtidos na experiência realizada em 2017 comprovam um desempenho de aprendizagem, em relação ao conteúdo, significativamente superior aos estudantes na mesma disciplina no ano de 2016, destacando-se aspectos como o compartilhamento de ideias e o confronto positivo entre os pares, além de uma maior interação entre a turma.

\section{Introdução}

Uma das maiores discussões sobre a qualidade e rumo da educação pública tem sido a formação docente e suas práticas pedagógicas. Há uma grande incógnita sobre esta geração de estudantes que mesmo tendo nas mãos muitas informações está se tornando protagonista de uma era em que a dificuldade de aprendizagem aumenta gradativamente.

A chegada da tecnologia e os laboratórios de informática às escolas públicas, que para muitos seria o suficiente para resolver, envolver e integrar os estudantes ao mundo virtual não passou de um sonho, pois ainda não houve a completa aceitação e utilização desse recurso para despertar o interesse e curiosidade dos estudantes a uma nova maneira de aprender. Mas também não é tarefa fácil para o professor, pois não basta só ter as 
máquinas, é preciso planejamento. Para Lévy (1999) as máquinas não trabalham sozinhas e por isso depende muito da intenção e planejamento pedagógico do professor.

Existe hoje uma vasta possibilidade de recursos tecnológicos que podem auxiliar o professor a planejar e executar atividades que permitam aos estudantes a vivenciar formas diferentes de estudar e aprender. Um desses recursos é o celular que já está presente no dia-a-dia da escola, inclusive dentro das salas de aula, porém ainda visto como um obstáculo na relação ensino-aprendizagem e por isso, muitas vezes, permanece guardado nas mochilas dos alunos, durante as aulas. Contrárias ao cenário atual é que se propõe o uso do celular como ferramenta pedagógica para contribuir com a aprendizagem dos alunos.

É com essa perspectiva que o presente trabalho oportuniza aos estudantes formas de interação e aprendizagem através do uso orientado do celular em sala de aula e sobretudo mediado pela metodologia ativa Peer Instruction. Segundo Souza(2012 p.47) "o dispositivo móvel tem potencial para ser utilizado numa grande variedade de métodos com finalidade de educação". Neste sentido entende-se que o celular poderá ser uma ótima ferramenta em sala de aula para promover o envolvimento dos estudantes, método este que propõe uma nova dinâmica para incentivá-los a buscar a compreensão sobre o conteúdo da disciplina e a conscientização do seu nível de conhecimento através de atividades de interação e aproximação para a construção coletiva e colaborativa do conhecimento. Para Silva et al. (2016 p.815), "Utilizar metodologias que venham integrar o uso de tecnologias e da aprendizagem a partir do interesse, curiosidade e investigação dos estudantes tem se tornado uma ótima opção para um ambiente de aprendizagem colaborativa". Essa colaboração e integração visa aumentar as condições de aprendizagem, respeitando as diferenças, dificuldades e habilidades individuais. Para Souza (2012 p.58)

\begin{abstract}
A orientação dos serviços educacionais baseados em tecnologia móvel é de dar aos estudantes ferramentas alternativas para apoiar e potencializar a construção de conhecimento e facilitar o trabalho colaborativo em uma aula, também de brindar de instrumentos que permitam criar um ambiente de estudo amigável, já que o caráter lúdico dos materiais didáticos tecnológicos despertam um maior interesse, e facilitam a aprendizagem. Souza (2012 p.58).
\end{abstract}

Diante deste contexto, buscando construir um ambiente colaborativo e lúdico, relata-se uma experiência positiva aplicada para incentivar os estudantes a estudar e compreender os conteúdos das disciplinas quando motivados ao uso do celular, descrevendo sua contribuição para o aprendizado.

\title{
2. $O$ uso de celulares na sala de aula
}

$\mathrm{O}$ avanço tecnológico e a rápida multiplicação dos celulares, principalmente, entre o público mais jovem tem causado grandes desafios quanto aos parâmetros e limites da sua utilização. A facilidade de acesso à internet, pacotes de dados das operadoras ou redes sem fio disponível em vários locais está fazendo com que crianças, jovens e adultos se mantenham cada vez mais ligados ao mundo virtual.

Nas escolas não é diferente e para alguns educadores isso passa a ser um grande desafio, pois o celular que antes era utilizado apenas para se comunicar e de forma mais restrita, com a evolução dos dispositivos móveis e suas novas funcionalidades esse cenário se transformou, o que facilitou o uso excessivo e camuflado pelos estudantes em todos os espaços, inclusive na sala de aula, pois podem: pesquisar, fotografar, filmar, 
enviar e-mail, trocar mensagens. Essa nova postura de acesso ilimitado e indiscriminado ás mídias eletrônicas podem prejudicar a aprendizagem dos estudantes devido à falta de atenção ao conteúdo de cada disciplina. É diante dessas constatações somado ao desafio de mantê-los atentos as atividades em sala de aula, a maioria das escolas não permitem a utilização desses aparelhos eletrônicos, inclusive orientam a deixá-los em casa.

Por outro lado, existem autores como Levy(2013) que defendem a utilização dos celulares em sala, afirmando o papel importante do professor em se preparar e apresentar essa nova realidade aos estudantes, ensinando-os a ter o domínio sobre si, ter disciplina, aprender quando ligar e desligar o aparelho durante as aulas.

São várias as oportunidades de utilização das ferramentas tecnológicas, armazenar os mais diversos dados como: áudio, vídeo, imagens e textos. Também é possível aproveitar suas funções no entretenimento, através dos jogos, vídeos e ainda facilitar as relações sociais agilizando a comunicação e também compartilhando informações. De acordo com Soares, et al. (2016, p. 580)

$\mathrm{O}$ acentuado crescimento tecnológico e o alto consumo de smartphones (telefones inteligentes com várias mídias num só aparelho) popularizam seu uso, em um público cada vez mais jovem. Para essa "geração polegar" que nasceu submersa na tecnologia móvel, fazer o uso dos recursos disponíveis pode ser produtivo e eficiente no ambiente escolar.

Aproveitando todo avanço tecnológico e crescimento na utilização de celulares por crianças, jovens e adultos é que surge a ideia de avaliarmos a contribuição dessa ferramenta para o aprendizado dos estudantes, pois de acordo com Alves e Vieira (2015):

Uma das maiores dificuldades enfrentadas pelo docente é lidar com o novo e buscar um novo olhar sobre o trabalho que é desenvolvido em sala, usando as novas tecnologias, inclusive o celular, torna-se um grande desafio. Porém, impedir o aluno de utilizar esses novos dispositivos eletrônicos durante as aulas é "andar na contramão" neste século. (p.238)

Considerando a motivação de acompanhar a evolução tecnológica e enfrentando os desafios como docentes optamos por utilizar o celular em sala de aula para avaliar os benefícios durante a atividade com os estudantes e para isso utilizamos o método Peer Instruction para mediarmos está prática.

\section{O Método Peer Instruction}

Peer Instruction (PI), proposto por Mazur (1997) é considerado um método que prevê a interação entre pares. A essência do método está "baseado no estudo prévio de materiais disponibilizados pelo professor e apresentação de questões conceituais, em sala de aula, para os estudantes discutirem entre si" (ARAUJO; MAZUR, 2013, p. 367). Os autores ainda destacam a melhoria da aprendizagem e a interação de estudantes como ações diferenciais do método. O ponto central da PI é a questão conceitual que não deve ser nem tão fácil e nem muito complexa para possibilitar ao professor avaliar, logo após a explanação ou apresentação do conteúdo, a compreensão dos conceitos fundamentais e com isso permitir um retorno imediato da aprendizagem. Lasry et al. (2008) ilustram todos os momentos do método PI, sendo que Araujo e Mazur (2013) adaptaram, destacando todas ações derivadas da questão conceitual conforme figura 1. 
VI Congresso Brasileiro de Informática na Educação (CBIE 2017)

Anais do XXIII Workshop de Informática na Escola (WIE 2017)

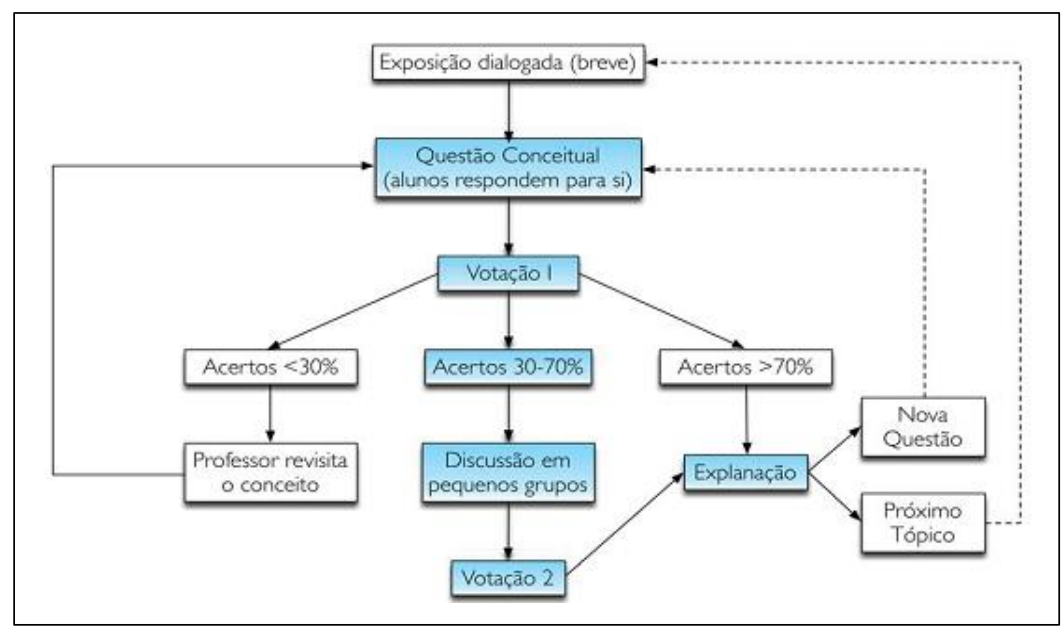

Figura 1 - Método Peer Instruction, Araujo e Mazur (2013, pag. 367)

Na figura 1, após a questão conceitual, que deverá ser objetiva, é realizado a votação 1 que pode ser mediada por diversos recursos, dependendo da disponibilidade desses pelo professor, podendo ser através de clickers, celular, flashcard ou até mesmo de forma manual. Esta última pode dificultar a análise do professor e favorecer possíveis "colas" entre os estudantes. No término da votação o professor irá verificar as porcentagens de acertos, se estas estiverem entre 30 a 70\%, ocorre neste momento a reunião de pequenos grupos de estudantes que irão discutir sobre suas escolhas e opiniões, procurando entender a partir desta interação a questão conceitual e o porquê das divergências de respostas. Ao final ocorre uma segunda votação, permitindo ao professor verificar se houve uma mudança nas escolhas provocadas pela discussão entre os pares, culminando com encerramento da questão com a explicação final. O processo pode ter um ciclo contínuo, dependendo do feedback da turma, reiniciando com uma nova questão ou um próximo tópico.

A dinâmica promovida pelo método que apoia um ambiente de aprendizagem centrado nos estudantes, segundo Porter et al. (2013), permite que a explicação tradicional seja substituída por perguntas destinadas a envolver os estudantes nesta compreensão estimulada entre os pares. Existe um conjunto significativo de pesquisas e relatos de inserção da PI na sala de aula com destaque para Pollock (2009) que introduziu o método nas aulas de física no ensino superior, o que melhorou significativamente o desempenho de estudantes e a participação em aula.

A pesquisa realizada por Perez et al. (2010) retratam a experiência da PI em um curso introdutório de biologia com a utilização de clickers para a votação, além dos resultados positivos com a adoção do método, os autores descobriram que após a primeira votação ao ver no gráfico de barras a resposta mais comum, mesmo sem saber se estava correto, os estudantes tinham a tendência de escolher esta resposta na segunda votação, o que poderia dar uma falsa impressão de melhoria no desempenho da turma, neste sentido a melhor estratégia é a não revelação da porcentagem de cada alternativa escolhida.

Outro estudo que aborda os benefícios da PI é apresentado por Cummings et al. (2008), o trabalho mostra os resultados em turmas de física e álgebra no ensino médio com a participação de mais de 100 estudantes. Os autores analisaram turmas com a 
pedagogia tradicional baseado na exposição de conteúdos e turmas com a inserção da PI, os pesquisadores constataram que a medida que o tamanho da turma aumenta, a quantidade de tempo em que cada estudante tem oportunidade de interagir com o professor diminui, o que reduz também a chance desse estudante contribuir com a aula. Por outro lado, em turmas que implementam o método PI, ao facilitar as discussões em pequenos grupos, os estudantes são favorecidos por um ambiente menos intimidante, propiciando a fala com o mesmo número de colegas, independentemente do tamanho da turma, o que os torna mais dispostos a também cooperar com toda a turma.

Kielt et al. (2017) também traz novos estudos com a prática do método PI no ensino médio desenvolvidas nas aulas de física. Além da utilização nas aulas, a pesquisa trouxe como contribuição a implementação de uma aplicação para smartfhone para subsidiar as votações eletrônicas. Segundo os autores, além de agilizar a conferências das respostas, o professor pode salva-las no seu computador para posteriormente acompanhar o histórico de evolução de cada estudante. Como resultados a introdução da PI em sala de aula mostrou-se como um eficiente instrumento para estimular a aprendizagem e a participação. Miller et al. (2012) também traz a implementação da PI em aulas de física do ensino médio com auxílio do projeto "UCA" (Um Computador por Aluno) como sistema de votação, apresentando-se com uma excelente ferramenta para complementação das atividades.

Igualmente as demais pesquisas citadas que implementaram a PI no ensino superior e médio, também existem estudos com efeitos positivos na educação profissional, o trabalho de Brandão Junior e Neves (2014) apresentam um experimento na disciplina de lógica de programação com resultados, que segundo os autores, aumentaram a motivação em sala de aula; Lima et al. (2016) também introduzem o método na disciplina de lógica de programação para trabalhar o conceito de estrutura de dados obtendo melhoras no aproveitamento ao final do curso. Já nos estudos investigados por Oliveira et al. (2017), a PI foi inserida nas turmas de novatos e experientes na disciplina de algoritmos e programação, evidenciando um aumento no engajamento e desempenho dos estudantes, mas com resultados divergentes na aceitação do método por parte dos alunos experientes. Nas pesquisas de Porter e Simon (2013) a PI foi eleita como uma das três melhores práticas para melhorar a qualidade do curso na área de computação com resultados comprovados nos índices de retenção.

As pesquisas supracitadas demonstram as potencialidades do método PI em sala de aula nos mais diversos níveis de ensino, o que confirma a eficácia da PI como uma pedagogia engajadora.

\section{Metodologia}

A experiência realizada e apresentada neste artigo envolve uma turma de 20 estudantes do primeiro ano de uma escola técnica do curso de Informática integrado ao Ensino Médio, denominada na pesquisa como turma experimental. Os conteúdos trabalhados da lógica compreendem a lógica proposicional e tabelas-verdade. As dinâmicas das aulas seguiram a estrutura PI e foram executadas entre os meses de março a maio de 2017.

A proposta foi adaptar o método PI e aplicar com o objetivo de reforçar ou retomar o conteúdo estudado através da avaliação. Durante a apresentação da proposta os estudantes testaram a dinâmica, com intuito de entender o funcionamento e esclarer 
dúvidas sobre a sua utilização. Eles foram avisados que teriam uma avaliação na próxima aula sobre o último conteúdo estudado. Esta proposta de prática surgiu com o objetivo principal de motivar o estudo extraclasse, o qual é justificada por uma pesquisa realizada pela instituição em que revelou a taxa de $10 \%$ de estudantes que afirmam estudar fora do horário da aula. As turmas da modalidade técnico integrado ao ensino médio tem como peculiaridades uma grade extensa de disciplinas, o que favorece esse comportamento dos estudantes de não estudar fora do horário da sala de aula ou mesmo estudar apenas nas vésperas de avaliações.

Para a realização da questão conceitual e votação foi utilizado o celular, uma vez que todos da turma dispõem desse recurso e acesso à internet que é disponibilizada pela escola. A ferramenta Kahoot foi também inserida nesta experiência, o que permitiu o registro das respostas dos estudantes. Kahoot é uma ferramenta de aprendizagem, online e gratuita, que segue o princípio de games, oferecendo ao professor uma maneira interativa de promover discussões e avaliar a turma por meio de perguntas, sendo de fácil acesso e disponível para dispositivos móveis (KAHOOT, 2017; IZEKI et al., 2016). Uma das principais funcionalidades é o armazenamento das respostas dos estudantes, geração de ranking dos cinco primeiros, contagem de tempo e relatórios em formato de planilha eletrônica, o que facilita para o professor analisar as respostas. Ao final da experiência foi realizado um teste com os conteúdos trabalhados e comparados seu aproveitamento com o ano de 2016, que compreendia um total de 20 estudantes, denominada turma convencional, em que foi avaliado o mesmo conteúdo, no entanto com a metodologia tradicional baseada na exposição/explicação do conteúdo e exercitação.

\section{Discussões e Resultados}

O registro da experiência com a metodologia PI e o uso de celulares teve duração de (7 semanas). Percebeu-se uma mudança gradual a partir da segunda aula, com estudantes mais preparados para as questões conceituais, o que foi identificado uma motivação aparente por esse momento.

Um dos pontos importantes do método PI é a questão conceitual, que deve ser desafiadora, sendo este um diferencial. A cada aula as questões eram mais elaboradas e envolviam o conteúdo da aula anterior. Um exemplo de questão pode ser visto na figura 2. O tempo de resposta era cronometrado e geralmente variava entre 60 a 90 segundos. Cada questão oferecia quatro alternativas de respostas e gradualmente o nível de complexidade era aumentado.

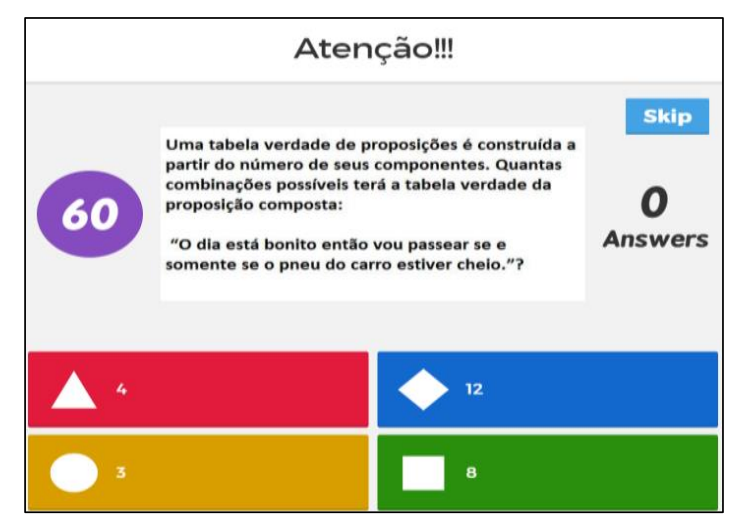

Figura 2. Exemplo de questão conceitual realizado no experimento. 
VI Congresso Brasileiro de Informática na Educação (CBIE 2017)

Anais do XXIII Workshop de Informática na Escola (WIE 2017)

A questão é projetada e os estudantes respondem pelo celular. Após registrarem todas as respostas dentro do tempo determinado, o professor verifica a porcentagem de acerto, se ficarem entre 30 a $70 \%$, a turma se divide em grupos de dois ou três integrantes, procurando divergências nas suas escolhas, neste momento ocorrerá uma discussão entre o grupo, onde irão identificar qual a resposta correta para a questão. Após este tempo decorrido, entre 5 a 7 minutos os estudantes respondem à questão novamente, a tendência é que aumente o número de acertos, situação que se confirmou na maioria das vezes. A figura 3 mostra o registro do momento da interação com o celular, onde os estudantes escolhem a alternativa.

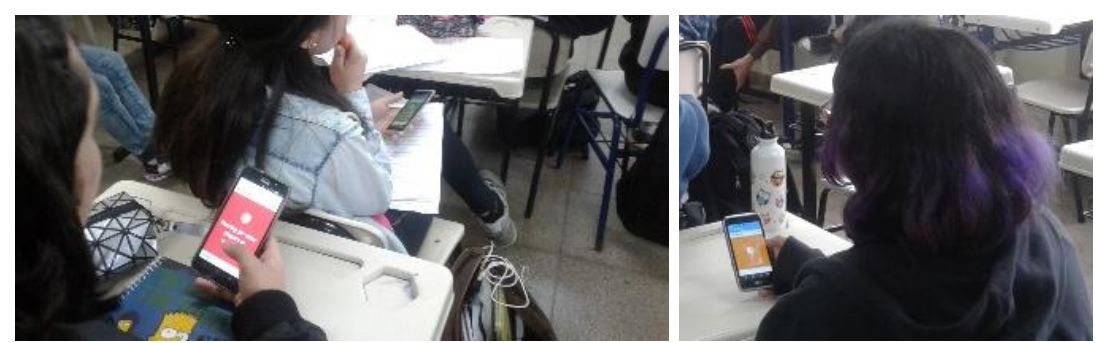

Figura 3. Estudantes registram as respostas pelo celular.

Na figura 4 é visualizado o momento em que o ranking é mostrado para todos os estudantes. Nesta opção o professor pode selecionar se deseja que a alternativa correta apareça juntamente com a quantidade de acertadores. No experimento não se mostrou, justamente para verificar a porcentagem de acerto, onde nesse momento congelava-se a projeção para assim fazer a checagem. A alternativa correta somente surgia nos momentos em que a pergunta era refeita. Se a porcentagem de acertos permanecesse baixa, o professor fazia a correção e explicava a questão.

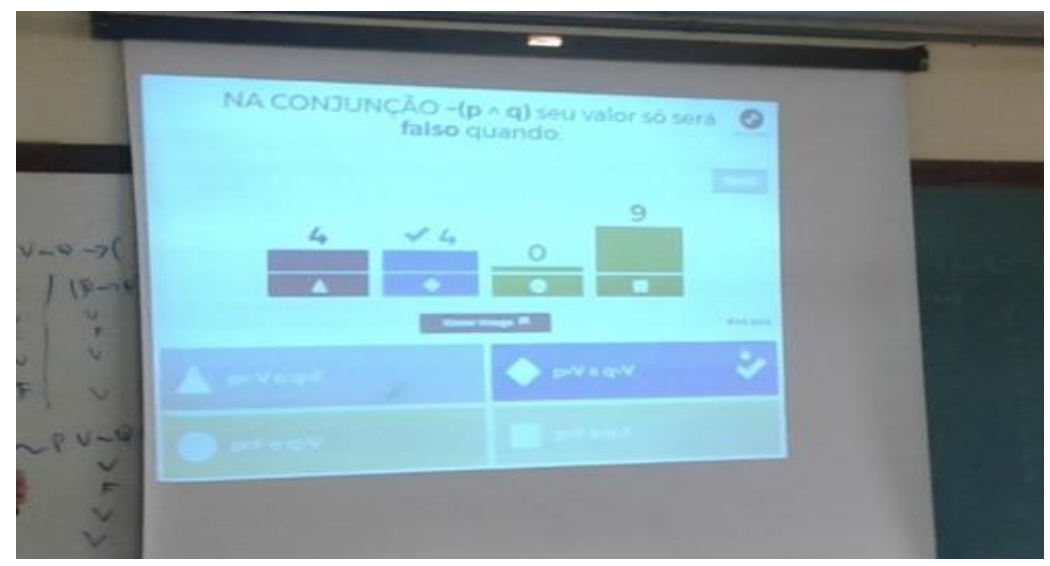

Figura 4. Ranking dos resultados.

Ao final do experimento com a turma foi realizado um teste para medir a aprendizagem dos conceitos trabalhados neste módulo e comparados com o ano de 2016, que também trabalhou o mesmo conteúdo, no entanto com a metodologia tradicional.

Para analisar os resultados e investigar as diferenças entre as duas amostras, utilizaram-se o Teste t de Student de Pares, conforme pode ser visto na tabela 1 a média da turma experimental foi significativamente maior em relação a turma convencional, no 
VI Congresso Brasileiro de Informática na Educação (CBIE 2017)

Anais do XXIII Workshop de Informática na Escola (WIE 2017)

entanto, percebe-se com a variância que as irregularidades das médias de ambas as turmas são baixas, tendo uma pequena diferença entre elas.

Diante disto, através do teste t de Student se confirmou a validade da hipótese de que a utilização do método PI combinado com o uso de dispositivos móveis melhorou o desempenho dos estudantes quanto ao aprendizado, obtendo-se um valor inferior a 5\%, o que valida o método de avaliação.

Tabela 1. Diferenças entre as turmas Convencional e Experimental

\begin{tabular}{|l|r|r|}
\hline & Turma Convencional & Turma Experimental \\
\hline Média & 3,3 & 7,69 \\
\hline Variância & 3,29 & 4,13 \\
\hline Teste $t$ & 0,000000054 \\
\hline
\end{tabular}

Para avaliar a satisfação com o método PI e o uso de celulares nas aulas, foi realizado um questionário com um escala likert que variava de muito ruim a muito bom em que foi perguntado sobre a abordagem usada nas aulas de lógica. Pode-se constatar no gráfico 1 que dos 20 participantes, 19 tiveram uma avaliação positiva, sendo que esses mesmo 19 estudantes também acreditam que a abordagem auxilia na aprendizagem.

\section{Gráfico 1- Satisfação com abordagem em sala de aula}

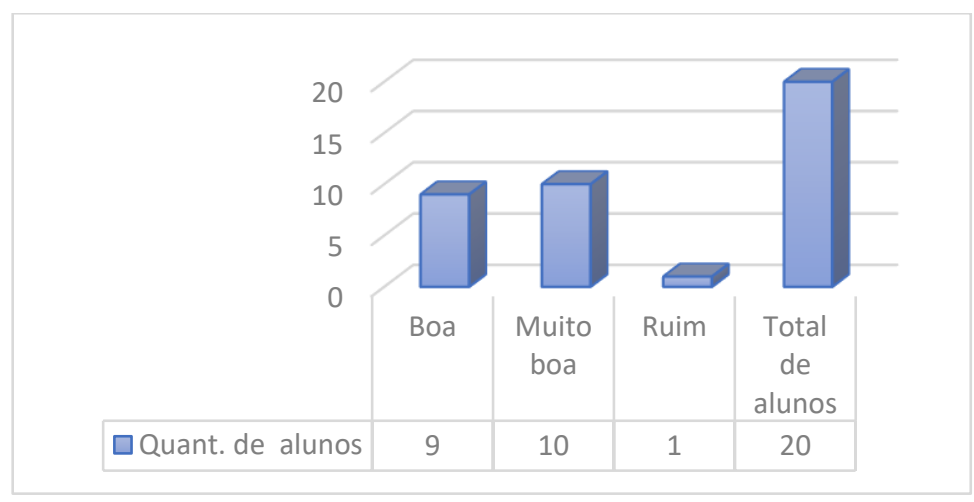

Os resultados positivos tanto na avaliação dos estudantes quanto no desempenho em relação a aprendizagem mostram que a união de um método eficaz juntamente com uma tecnologia que está ao alcance de todos podem provocar mudanças significativas num ambiente de ensino, tornando mais atrativo e motivador para o estudante aprender.

\section{Considerações Finais}

O trabalho mostrou a experiência realizada com uma turma do curso Técnico em Informática integrado ao Ensino Médio de uma escola técnica. A proposta foi inovar as aulas de Lógica por meio do celular juntamente com uma prática de ensino diferenciada a Peer Instruction. Os resultados demonstraram um maior envolvimento dos estudantes nas aulas e principalmente os motivou para o estudo extraclasse, sendo este um dos 
VI Congresso Brasileiro de Informática na Educação (CBIE 2017)

Anais do XXIII Workshop de Informática na Escola (WIE 2017)

maiores problemas, que refletia no desempenho no curso.

A partir das análises dos resultados pode-se perceber alguns aspectos positivos durante o experimento, como o trabalho colaborativo, que incentivou o compartilhamento de ideias, o confronto positivo, a assistência entre os pares promovida com a reunião em pequenos grupos o que gerou uma maior interação entre a turma. Outro aspecto enriquecedor e diferencial para aprendizagem foi o feedback imediato entre os pares e o reforço que foi evidenciando pela experiência, o que se mostrou uma prática eficaz. Como pontos a serem considerados, o método necessita de um planejamento prévio do professor e rigor na sua aplicação, principalmente no que tange ao tempo para cada momento.

Por fim, pretende-se a partir desses resultados ampliar a utilização desta prática para mais turmas do curso e com isso proporcionar experiencias inovadoras através das tecnologias de informação e comunicação.

\section{Referências}

Alves, E. D. G, Vieira M. de F.(2015) "Celular e sala de aula: dos limites às possibilidades" Anais do XXI Workshop de Informática na Escola (WIE 2015). Disponível em: <http://www.br-ie.org/pub/index.php/wie/article/view/5029/3439> Acesso em: 30 maio 2017.

Araújo, I. S., Mazur, E. (2013) “Instrução pelos Colegas e Ensino sob Medida: uma proposta para o engajamento dos alunos no processo de ensino-aprendizagem de Física". Caderno Brasileiro de Ensino de Física, v. 30, n. 2: p. 362-384.

Brandão Junior, J. A.; Neves, J. M. S. (2014) "Aplicação da Metodologia "Peer Instruction" em um curso técnico em Informática". IX Workshop de Pós-Graduação e Pesquisa do Centro Paula Souza. Estratégias Globais e Sistemas Produtivos Brasileiros.

Cummings, K., Roberts, S. G., Henderson, C., Sabella, M. e Hsu, L. (2008) "A Study of Peer Instruction Methods with High School Physics Students". Physics Education Research Conference, Edmonton, Canada. vol. 1064 of PER Conference, pp. 103-106.

Izeki, C. A.; N., Walter A.; Dias, R. M. C.. "Experiência no Uso de Ferramentas Online Gamificadas na Introdução à Programação de Computadores". Anais do XXII Workshop de Informática na Escola (WIE 2016), p. 301-310, 2016.

Kahoot. Make Learning Awesome. Disponível em: <https://getkahoot.com/>. Acesso em: 20/03/2017.

Kielt, Everton Donizetti; Da Silva, Sani de Carvalho Rutz; Miquelin, Awdry Feisser. (2017). "Implementação de um aplicativo para smartphones como sistema de votação em aulas de Física com Peer Instruction”. Revista Brasileira de Ensino de Física, vol. $39, \mathrm{n}^{\circ} 4$, e4405.

Lévy, Pierre. (1999) Cibercultura. Rio de Janeiro: Disponível em: $<$ https://scholar.google.com/scholar_lookup?title $=+$ Cibercultura\&author $=\mathrm{L} \% \mathrm{C} 3 \% 8$ 9VY+Pierre.\&publication_year=1999 $>$ Acesso em 25 maio 2017.

Lévy, P (2013) Pierre Lévy fala dos benefícios das ferramentas virtuais para o ensino (Matéria publicada na edição de fev. de 2013 da revista Gestão Educacional) Disponível em: <http://www.webaula.com.br/index.php/pt/acontece/noticias/2874- 
VI Congresso Brasileiro de Informática na Educação (CBIE 2017)

Anais do XXIII Workshop de Informática na Escola (WIE 2017)

pierre-levy-fala-dos-beneficios-das-ferramentas-virtuais-para-a-educacao $>$. Acesso em: 27 maio 2017.

Lima, S. J. S. de; Silva, E. F. da; Alves, V. M.; Castanho, C. L. O.; Espindola, P.; Bachinsk, R. E. (2016) "Aplicação de uma Metodologia Ativa para o Ensino de Lógica de Programação". Anais do EATI - Encontro Anual de Tecnologia da Informação e STIN - Simpósio de tecnologia da Informação da Região Noroeste do RS, Frederico Westphalen - RS, Ano 6 n. 1 p. 209-212. Disponível em: < http://eati.info/eati/2016/assets/anais/Curtos/209.pdf>. Acesso em 26 de Agosto 2017.

Mazur, E. (1997) Peer instruction: A user's manual. Pap/Dskt ed. [S.1.] Prentice Hall, Inc., p. 253.

Müller, M. G. et al. Implementação do método de ensino Peer Instruction com o auxílio dos computadores do projeto "UCA" em aulas de Física do Ensino Médio. Caderno Brasileiro de Ensino de Física, v. 29, n. Especial 1, p. 491-524, 2012.

Oliveira, M.A.F; LIMA, J. V. ; CANTO FILHO, A. B. ; NUNES, F. B. ; LOUREGA, L. V. ; MELO, J. N. B. (2017) "Aplicação do método Peer Instruction no ensino de Algoritmos e programação de computadores”. RENOTE. Revista Novas Tecnologias Na Educação, v. 15, p. 1-10.

Perez, K. E.; Strauss, E. A.; Downey, N. (2010) "Does Displaying the Class Results Affect Student Discussion during Peer Instruction?”. Education. vol. 9, pp. 133-140.

Pollock, S. (2009) "Longitudinal study of student conceptual understanding in electricity and magnetism". Physical Review Special Topics - Physics Education Research, vol. 5. $\mathrm{n}^{\mathrm{o}}$. 2, pp. 1-8.

Porter, Leo; Bailey-Lee, Cynthia; Simon, Beth.( 2013) "Halving Fail Rates using Peer Instruction: A Study of Four Computer Science Courses”. SIGCSE'13, March 6-9, Denver, Colorado, USA.

Porter, L.; SIMON, Beth. (2013) Retaining Nearly One-Third more Majors with a Trio of Instructional Best Practices in CS1. SIGCSE'13, March 6-9, Denver, Colorado, USA.

Silva, Patrícia F. da; Menezes, Crediné S. de; Fagundes, Léa da Cruz. (2016) "Aprendizagem colaborativa: desenvolvimento de Projetos de Aprendizagem em ambientes digitais". Disponível em: $<$ http://www.brie.org/pub/index.php/wie/article/view/6625/4536>. Acesso em: 10 de Abril 2016.

Soares, N. Almeida, C. Saraiva, J. (2016): “Inovações Tecnológicas em Escolas Públicas: Análise de Fatores Motivadores". V Congresso Brasileiro de Informática na Educação (CBIE 2016). DOI: 10.5753/cbie.wie.2016.291. Disponível < http://www.brie.org/pub/index.php/wie/article/viewFile/6647/4558>Acesso em: 25 maio 2017.

Souza, Bruno de (2012) Mobile Learning: Educação e Tecnologia na palma da mão Bruno de Souza. - Cariacica: Mobile Learningpedia. 